\title{
Calcium Homeostasis Is Altered in Skeletal Muscle of Spontaneously Hypertensive Rats
}

\section{Cytofluorimetric and Gene Expression Analysis}

\author{
Antonella Liantonio, ${ }^{*}$ Giulia M. Camerino, ${ }^{*}$ Antonia Scaramuzzi, ${ }^{*}$ Maria Cannone, ${ }^{*}$ Sabata Pierno, ${ }^{*}$ Michela De Bellis, * \\ Elena Conte, ${ }^{*}$ Bodvael Fraysse, ${ }^{\dagger}$ Domenico Tricarico, ${ }^{*}$ and Diana Conte Camerino*
}

From the Section of Pharmacology, ${ }^{*}$ Department of Pharmacy-Drug Sciences, University of Bari, Bari, Italy; and INRA UMR703, ${ }^{\dagger}$ LUNAM Université, Oniris, École Nationale Vétérinaire, Agro-Alimentaire et de l'Alimentation Nantes-Atlantique, Nantes, France

\author{
Accepted for publication \\ June 17, 2014. \\ Address correspondence to \\ Antonella Liantonio, Ph.D., \\ Section of Pharmacology, \\ Department of Pharmacy-Drug \\ Sciences, University of Bari, Via \\ Orabona 4, CAMPUS, 70125 \\ Bari, Italy. E-mail: antonella \\ liantonio@uniba.it.
}

\begin{abstract}
Hypertension is often associated with skeletal muscle pathological conditions related to function and metabolism. The mechanisms underlying the development of these pathological conditions remain undefined. Because calcium homeostasis is a biomarker of muscle function, we assessed whether it is altered in hypertensive muscles. We measured resting intracellular calcium and store-operated calcium entry (SOCE) in fast- and slow-twitch muscle fibers from normotensive Wistar-Kyoto rats and spontaneously hypertensive rats (SHRs) by cytofluorimetric technique and determined the expression of SOCE gene machinery by real-time PCR. Hypertension caused a phenotype-dependent dysregulation of calcium homeostasis; the resting intracellular calcium of extensor digitorum longus and soleus muscles of SHRs were differently altered with respect to the related muscle of normotensive animals. In addition, soleus muscles of SHR showed reduced activity of the sarcoplasmic reticulum and decreased sarcolemmal calcium permeability at rest and after SOCE activation. Accordingly, we found an alteration of the expression levels of some SOCE components, such as stromal interaction molecule 1, calcium release-activated calcium modulator 1, and transient receptor potential canonical 1. The hypertension-induced alterations of calcium homeostasis in the soleus muscle of SHRs occurred with changes of some functional outcomes as excitability and resting chloride conductance. We provide suitable targets for therapeutic interventions aimed at counterbalancing muscle performance decline in hypertension, and propose the reported calcium-dependent parameters as indexes to predict how the antihypertensive drugs could influence muscle function. (Am J Pathol 2014, 184: 2803-2815; http://dx.doi.org/10.1016/j.ajpath.2014.06.020)
\end{abstract}

Hypertension is a multifactorial disease, characterized by an increase of blood pressure associated with an increased risk of organ damage. Other than impairing cardiomyocytes' functionality, the alteration of microcirculation affects skeletal muscle physiological features, resulting in a significant increase in fatigue and muscle weakness in hypertensive patients during exercise. ${ }^{1-5}$ Although it is still controversial whether the microvessel rarefaction is a cause or a result of blood pressure elevation, a growing body of evidence indicates that skeletal muscles undergo a series of alterations regarding both function and metabolism. Specifically, structural and biochemical abnormalities have been reported in spontaneously hypertensive rat (SHR), the most widely used animal model of essential hypertension, when compared with the normotensive Wistar-Kyoto rat (WKY), including reduced cross-sectional area of muscle fibers, ${ }^{6}$ sarcomere disorganized structure, ${ }^{7}$ altered $\mathrm{Na}^{+} / \mathrm{K}^{+}$pump number and activity, ${ }^{8}$ reduced sensitivity to insulin, ${ }^{9}$ elevated cellular stress markers, ${ }^{10}$ and apoptotic signaling. ${ }^{11,12}$ Furthermore, fiber-type redistribution $^{7,13,14}$ and muscle-type-specific modification of autophagy markers ${ }^{15}$ have been reported in muscles of SHR with respect to WKY animals.

\footnotetext{
Supported by the Italian Ministry of Education, MIUR-COFIN-2009, and
} Telethon GGP10101 (D.C.C.)

Disclosures: None declared. 
Calcium ion plays a pivotal role in sustaining muscle performance, controlling its contractile properties and regulating the gene expression profile of fiber-specific proteins. ${ }^{16}$ Accordingly, in previous studies, we showed a close correlation between the phenotype transition of slow- to fast-twitch muscle fibers and the alteration of calcium homeostasis in rodent soleus muscle during disuse. ${ }^{17,18}$ Furthermore, it has been widely demonstrated that the store-operated calcium entry (SOCE) is a rapidly activated, robust mechanism in skeletal muscle, essential for maintenance of $\mathrm{Ca}^{2+}$ homeostasis by ensuring the refilling of intracellular calcium storage. ${ }^{19,20}$ Physiological SOCE is required for proper muscle function. Indeed, excessive SOCE contributes to the progression of muscle deterioration in muscular dystrophy, ${ }^{21,22}$ whereas reduced SOCE is associated with muscle performance decline during aging. ${ }^{23}$

To test the hypothesis that hypertension could cause a dysregulation of skeletal muscle calcium homeostasis, we used fura-2 acetoxymethyl ester (fura-2) fluorescence to investigate $\mathrm{Ca}^{2+}$ signaling and to evaluate the functional status of SOCE in tendon-to-tendon-isolated fast- and slow-twitch skeletal muscle fibers of SHR and WKY rats. Furthermore, to gain insight into the SOCE machinery, we compared the expression levels of SOCE components in WKY and SHR muscles using real-time PCR. Finally, to evaluate whether the hypertension-induced alteration in calcium homeostasis interferes with muscle function, we determined muscle excitability and the resting chloride conductance $(\mathrm{gCl})$, a parameter that controls the electrical stability of sarcolemma, ${ }^{24,25}$ by electrophysiological techniques.

Our data show that calcium homeostasis is dysregulated in skeletal muscles of SHR animals in a phenotypedependent manner. Given the crucial role of calcium ions in skeletal muscle function and maintenance, these findings contribute to elucidate the mechanisms underlying hypertension-induced muscle contractile dysfunction and identify druggable targets for the treatment of muscle weakness affecting hypertensive patients.

\section{Materials and Methods}

\section{Animal Care}

Animal care and all experimental protocols involving animals were in accordance with the European Directive 2010/63/EU and were approved by the Italian Ministry of Health. Male SHR (aged 15 to 17 weeks) and age-matched normotensive WKY control rats were purchased from Charles River Laboratories (Calco, Italy). Animals ( $n=15$ for each group) were housed in a temperature-, humidity-, and light-controlled room.

\section{Blood Pressure Measurements}

Systolic blood pressure (SBP) was measured noninvasively in conscious, prewarmed, restrained rats using a tail-cuff BP-2000 Blood Pressure Analysis System
(Visitech System Inc., Apex, NC), according to previously described procedures. ${ }^{26,27}$ The reported SBP values are the average of three sequential blood pressure measurements that were within $10 \mathrm{mmHg}$ of each other.

\section{Dissection of Native Muscle Fibers}

The extensor digitorum longus (EDL) and soleus muscles were removed from each animal under deep urethane anesthesia $(1.2 \mathrm{~g} / \mathrm{kg}$ body weight). Immediately after the surgery, the rats were maintained under anesthesia and euthanized with an anesthetic overdose. EDL and soleus muscles were pinned in a dissecting dish containing $95 \%$ $\mathrm{O}_{2} / 5 \% \mathrm{CO}_{2}$-gassed normal physiological solution (composition defined later) at room temperature $\left(22^{\circ} \mathrm{C}\right)$ for further dissection. Small bundles of 10 to 15 fibers arranged in a single layer were dissected lengthwise (tendon to tendon) with the use of microscissors, as previously described. ${ }^{17}$

\section{Fura-2 Fluorescence Measurements in Intact Muscle} Fibers

Calcium measurements were performed using the membranepermeable $\mathrm{Ca}^{2+}$ indicator, fura-2 AM (Molecular ProbesInvitrogen, Monza, Italy). Loading of muscle fibers was performed for 2 hours at $25^{\circ} \mathrm{C}$ in normal physiological solution containing $5 \mu \mathrm{mol} / \mathrm{L}$ fura- $2 \mathrm{AM}$ mixed to $0.05 \%$ (v/v) Pluronic F-127 (Molecular Probes). After loading, muscle fibers were washed with normal physiological solution and mounted in a modified RC-27NE experimental chamber (Warner Instrument Inc., Hamden, CT) on the stage of an inverted Eclipse TE300 microscope (Nikon, Tokyo, Japan) with a $40 \times$ PlanFluor objective (Nikon). The mean sarcomere length was set to 2.5 to $2.7 \mu \mathrm{m}$. Fluorescence measurements were made using a QuantiCell 900 integrated imaging system (Visitech International Ltd, Sunderland, UK), as previously described. ${ }^{17,28}$

During the experiments, pairs of background-subtracted images of fura-2 fluorescence $(510 \mathrm{~nm})$, emitted after excitation at 340 and $380 \mathrm{~nm}$, were acquired and ratiometric images $(340 / 380 \mathrm{~nm})$ were calculated for each muscle fiber of the preparation using QC2000 software (VisiTech International Ltd, Sunderland, UK). Subsequently, fluorescence ratio values were converted to the resting cytosolic calcium concentration, $\left[\mathrm{Ca}^{2+}\right] \mathrm{i}(\mathrm{nmol} / \mathrm{L})$, after a calibration procedure using the following equation:

$$
\left[\mathrm{Ca}^{2+}\right]_{\mathrm{i}}=\left(\mathrm{R}-\mathrm{R}_{\min }\right) /\left(\mathrm{R}_{\max }-\mathrm{R}\right) * \mathrm{~K}_{\mathrm{D}} * \beta
$$

where $R$ is the ratio of the fluorescence emitted after excitation at $340 \mathrm{~nm}$ to the fluorescence after excitation at $380 \mathrm{~nm}$; $K_{D}$ is the affinity constant of fura-2 for calcium, which was taken as $145 \mathrm{nmol} / \mathrm{L}$ (Molecular Probes); and $\beta$ is a parameter, according to Grynkiewicz et al, ${ }^{29}$ that was determined experimentally in situ in ionomycin-permeabilized muscle fibers, as previously described. ${ }^{17,29} \mathrm{R}_{\min }$ and $\mathrm{R}_{\max }$ (minimum and maximum, respectively) were determined in muscle fibers incubated in $\mathrm{Ca}^{2+}$-free normal physiological solution 
containing $10 \mathrm{mmol} / \mathrm{L}$ EGTA and in normal physiological solution, respectively. Because calibration parameters of fura-2 can depend on muscle type and experimental condition, ${ }^{17,28}$ we determined the parameters of the equation of Grynkiewicz et $\mathrm{al}^{29}$ in each muscle examined for accurate calculation of calcium concentration.

\section{Resting Calcium Entry and SOCE Measurements by $\mathrm{Mn}^{2+}$ Quenching Technique}

The manganese quench technique was used to estimate the sarcolemmal permeability to divalent cations. $\mathrm{Mn}^{2+}$ enters via the same routes as $\mathrm{Ca}^{2+}$ but accumulates inside the cell. As $\mathrm{Mn}^{2+}$ quenches the fluorescence of fura-2, the reduction of the intensity of fura-2 fluorescence can be used as an indicator of the time integral of $\mathrm{Mn}^{2+}$ influx. ${ }^{30}$ Muscle preparations were perfused for 2 minutes with normal physiological solution containing $0.5 \mathrm{mmol} / \mathrm{L} \mathrm{Mn}^{2+}$ as a surrogate of $\mathrm{CaCl}_{2}$ (quenching solution). To measure the $\mathrm{Mn}^{2+}$ influx through the SOC, a proper protocol for SOCE activation was used. ${ }^{19,31,32}$ Particularly, the fibers were perfused with $10 \mu \mathrm{mol} / \mathrm{L}$ thapsigargin and $40 \mathrm{mmol} / \mathrm{L}$ caffeine for 15 minutes in zero $\mathrm{Ca}^{2+}$ extracellular solution to induce sarcoplasmic reticulum (SR) $\mathrm{Ca}^{2+}$ depletion; successively, $0.5 \mathrm{mmol} / \mathrm{L} \mathrm{Mn}^{2+}$ was added to extracellular solution. During the quenching protocol, the fluorescence emission of fura-2, excited at $360 \mathrm{~nm}$, was acquired at $1 \mathrm{~Hz}$.

\section{Electrophysiological Recordings by Intracellular Microelectrodes}

Soon after removal, the soleus and EDL muscles were tied at each tendon on a glass rod in a $25-\mathrm{mL}$ chamber and perfused with the normal physiological solution at $30^{\circ} \mathrm{C}$, gassed with $95 \% \mathrm{O}_{2} / 5 \% \mathrm{CO}_{2}$. The resting sarcolemmal $\mathrm{gCl}$ was determined using the two intracellular microelectrodes technique in current-clamp mode, as detailed elsewhere. ${ }^{25}$ Briefly, the membrane resistance was calculated by injecting a hyperpolarizing square current pulse into the muscle fiber through one microelectrode and recording the resulting voltage deflection with a second microelectrode inserted at two different distances from the current electrode. The current stimulation and data acquisition and analysis were performed under computer control. The total membrane conductance $(\mathrm{gm})$ was $1 /$ membrane resistance in the normal physiological solution. The potassium conductance $(\mathrm{gK})$ was measured in a chloride-free physiological solution. The mean chloride conductance, $\mathrm{gCl}$, was calculated as the mean gm minus the mean gK. To measure the excitability characteristics of sampled fibers, the membrane potential was set by a steady holding current to $-80 \mathrm{mV}$ before passing the depolarizing pulses. By increasing the amplitude of the pulse, a single action potential was elicited. The excitability parameters, determined off-line on digital action potential recordings, were the current threshold to elicit the first action potential $\left(\mathrm{I}_{\mathrm{th}}\right)$ and the latency of action potential, which is the delay from the beginning of the current pulse to the onset of an action potential at threshold and is an excitability parameter inversely correlated to the $\mathrm{gCl}$.

\section{Solution and Chemical Compounds}

The normal physiological solution was composed of $148 \mathrm{mmol} / \mathrm{L} \mathrm{NaCl}, 4.5 \mathrm{mmol} / \mathrm{L} \mathrm{KCl}, 2.5 \mathrm{mmol} / \mathrm{L} \mathrm{CaCl}{ }_{2}$, $1 \mathrm{mmol} / \mathrm{L} \mathrm{MgCl}_{2}, 0.44 \mathrm{mmol} / \mathrm{L} \mathrm{NaH} \mathrm{PO}_{4}, 12 \mathrm{mmol} / \mathrm{L}$ $\mathrm{NaHCO}_{3}$, and $5.5 \mathrm{mmol} / \mathrm{L}$ glucose. The $\mathrm{pH}$ of all solutions was adjusted to 7.3 to 7.4 by bubbling them with $95 \% \mathrm{O}_{2} /$ $5 \% \mathrm{CO}_{2}$. To stimulate $\mathrm{Ca}^{2+}$ influx via $\mathrm{Na}^{+} / \mathrm{Ca}^{2+}$ exchanger, most of the $\mathrm{Na}^{+}$to the solution was replaced with $\mathrm{N}$ methyl-D-glucamine. ${ }^{33}$ The normal physiological solution was modified as follows: $\mathrm{CaCl}_{2}$ was omitted, and $10 \mathrm{mmol} / \mathrm{L}$ EGTA was added for calcium-free solution; $0.5 \mathrm{mmol} / \mathrm{L}$ $\mathrm{MnCl}_{2}$ was substituted for $\mathrm{CaCl}_{2}$ for quenching solution; methyl sulfate salts were substituted for $\mathrm{NaCl}$ and $\mathrm{KCl}$; and nitrate salts were substituted for $\mathrm{CaCl}_{2}$ and $\mathrm{MgCl}_{2}$ for chloride-free solution. All chemicals cited above and ionomycin, caffeine, and thapsigargin were purchased from Sigma (St. Louis, MO).

\section{Western Blot Analysis of RyR1 Expression}

Ryanodine receptor 1 (RyR1) was isolated according to Bastide et al. ${ }^{34}$ Briefly, soleus and EDL muscles were homogenized in ice-cold buffer containing $20 \mathrm{mmol} / \mathrm{L}$ HEPES (pH 7.4), $2 \mathrm{mmol} / \mathrm{L}$ EDTA, $0.2 \mathrm{mmol} / \mathrm{L}$ EGTA, $0.3 \mathrm{~mol} / \mathrm{L}$ sucrose, and $0.2 \mathrm{mmol} / \mathrm{L}$ phenylmethylsulfonyl fluoride. Homogenates were centrifuged at $7000 \times g$ for 5 minutes at $4^{\circ} \mathrm{C}$. The supernatant obtained was centrifuged at 100,000 $\times g$ for 90 minutes at $4^{\circ} \mathrm{C}$. Microsomal proteins were separated using 6\% SDS-PAGE and transferred onto nitrocellulose membranes for 1 hour at $200 \mathrm{~mA}$ (SemiDry transfer blot; Bio-Rad, Waltham, MA). Membranes were blocked for 2 hours with $0.2 \mathrm{~mol} / \mathrm{L}$ Tris- $\mathrm{HCl}, 1.5 \mathrm{~mol} / \mathrm{L}$ $\mathrm{NaCl}$, and $\mathrm{pH} 7.4$ buffer [Tris-buffered saline (TBS)] containing 5\% nonfat dry milk and $0.5 \%$ Tween-20. They were incubated overnight at $4{ }^{\circ} \mathrm{C}$ with the first antibody (mouse anti-RyR; clone 34C; Thermo Scientific Pierce, Berkeley, CA), diluted 1:2500 with TBS containing 5\% nonfat dry milk, washed three times with TBS containing $0.5 \%$ Tween20 , and then incubated for 1 hour with secondary antibody labeled with peroxidase (1:5000 rabbit anti-mouse IgG; Sigma-Aldrich, St. Louis, MO). Membranes were then washed with TBS and Tween 20 and developed with a chemiluminescent substrate (Clarity Western ECL Substrate; Bio-Rad).

\section{Isolation of Total RNA, Reverse Transcription, and Real-Time PCR}

For each soleus and EDL muscle sample, total RNA was isolated with TRIzol (Invitrogen-Life Technologies, 
Carlsbad, CA) and quantified using a spectrophotometer (ND-1000 NanoDrop; Thermo Scientific).

To degrade any DNA contamination in each sample, $1 \mu \mathrm{g}$ of the total RNA was incubated with $1 \mathrm{U}$ of DNase I (RNAse free; Ambion, Carlsbad, CA) at $37^{\circ} \mathrm{C}$ for $30 \mathrm{mi}-$ nutes and $75^{\circ} \mathrm{C}$ for 5 minutes.

To perform reverse transcription, for each sample, $400 \mathrm{ng}$ of total RNA was added to $1 \mu \mathrm{L}$ dNTP mix $(10 \mathrm{mmol} / \mathrm{L}$ each) (model 11277049001; Roche, Basilea, Switzerland) and $1 \mu \mathrm{L} 50 \mu \mathrm{mol} / \mathrm{L}$ random hexamers (model C.N. n808-0127; Life Technologies) incubated at $65^{\circ} \mathrm{C}$ for 5 minutes. Four microliters of $5 \times$ first standard buffer (model C.N. Y02321; Life Technologies), $2 \mu \mathrm{L}$ of $0.1 \mathrm{~mol} / \mathrm{L}$ dithiothreitol (model C.N. Y00147; Life Technologies), and $1 \mu \mathrm{L}$ of $40 \mathrm{U} / \mu \mathrm{L}$ recombinant RNasin ribonuclease inhibitor (model C.N. N2511; Promega, Fitchburg, WI) were then added, and the solution was incubated at $42^{\circ} \mathrm{C}$ for 2 minutes. One microliter of $200 \mathrm{U} / \mu \mathrm{L}$ SuperScript II Reverse Transcriptase (model C.N. 18064-014; Life Technologies) was then added to each solution and incubated at $25^{\circ} \mathrm{C}$ for 10 minutes, $42^{\circ} \mathrm{C}$ for 50 minutes, and $70^{\circ} \mathrm{C}$ for 15 minutes. Each reaction was performed as a singleplex real-time PCR. The setup of reactions consisted of $8 \mathrm{ng}$ of cDNA, $0.5 \mu \mathrm{L}$ of TaqMan gene expression assays (Life Technologies) for each gene, $5 \mu \mathrm{L}$ of $2 \times$ TaqMan Universal PCR master mix No AmpErase UNG (model C.N. 4324018; Life Technologies), and nuclease-free water (not diethyl-pyrocarbonate treated; model AM9930; Life Technologies), for a final volume of $10 \mu \mathrm{L}$. The RTTaqMan-PCR conditions were as follows: step $1,95^{\circ} \mathrm{C}$ for 20 seconds; step $2,95^{\circ} \mathrm{C}$ for 3 seconds; and step $3,60^{\circ} \mathrm{C}$ for 30 seconds. Steps 2 and 3 were repeated 40 times. The results were compared with the relative standard curve obtained by five points of 1:4 serial dilution. The mRNA expression of the genes was normalized to the housekeeping gene HPRT1 (Supplemental Table S1). To detect ORAII gene expression, the cDNA was pre-amplified. The setup of PreAmp reaction consisted of $200 \mathrm{ng}$ of cDNA, $25 \mu \mathrm{L}$ of $2 \times$ TaqMan PreAmp master mix (model PN 4384557; Invitrogen-Life Technologies, Carlsbad, CA), $12 \mu \mathrm{L}$ of each $0.2 \times$ TaqMan GenExpression Assays (ORAII and HPRT1), and nucleotide-free water, for a final volume of $50 \mu \mathrm{L}$. The PreAmp PCR conditions were as follows: $95^{\circ} \mathrm{C}$ for 10 minutes, $95^{\circ} \mathrm{C}$ for 15 seconds, and $60^{\circ} \mathrm{C}$ for 4 minutes. Steps 2 and 3 were repeated 10 times. The PreAmp products were diluted 1:5 with nucleotide-free water before real-time experiment. All real-time PCR experiments were conducted respecting Minimum Information for Publication of Quantitative Real-Time PCR Experiments guidelines. ${ }^{35}$

\section{Statistical Analysis}

The data are presented as the means \pm SEM. One-way analysis of variance, followed by Bonferroni's $t$-test, was used to evaluate multiple statistical differences between groups. $P<0.05$ was considered to be statistically significant.
Table 1 Summary of Animal Characteristics

\begin{tabular}{|c|c|c|}
\hline Experimental characteristic & WKY group & SHR group \\
\hline $\mathrm{SBP}(\mathrm{mmHg})$ & $\begin{array}{l}137 \pm 2.7 \\
(n=15)\end{array}$ & $\begin{array}{l}204 \pm 1.5 \\
(n=15)^{*}\end{array}$ \\
\hline Body weight $(\mathrm{g})$ & $\begin{array}{l}421 \pm 9.5 \\
(n=15)\end{array}$ & $\begin{array}{l}362 \pm 5.4 \\
(n=15)^{*}\end{array}$ \\
\hline \multicolumn{3}{|l|}{ EDL } \\
\hline Fiber diameter $(\mu \mathrm{m})$ & $\begin{array}{l}67.2 \pm 2.3 \\
(n=43)\end{array}$ & $\begin{array}{l}77.5 \pm 4.5 \\
(n=60)\end{array}$ \\
\hline $\begin{array}{l}\text { Muscle weight/body } \\
\text { weight }(\mathrm{mg} / \mathrm{g})\end{array}$ & $\begin{array}{l}0.47 \pm 0.006 \\
(n=12)\end{array}$ & $\begin{array}{l}0.49 \pm 0.005 \\
(n=12)\end{array}$ \\
\hline \multicolumn{3}{|l|}{ Soleus } \\
\hline Fiber diameter $(\mu \mathrm{m})$ & $\begin{array}{l}62.5 \pm 2.3 \\
(n=40)\end{array}$ & $\begin{array}{l}55.4 \pm 3.7 \\
(n=60)\end{array}$ \\
\hline $\begin{array}{l}\text { Muscle weight/body } \\
\text { weight }(\mathrm{mg} / \mathrm{g})\end{array}$ & $\begin{array}{l}0.52 \pm 0.012 \\
(n=12)\end{array}$ & $\begin{array}{l}0.46 \pm 0.012 \\
(n=12)^{\dagger}\end{array}$ \\
\hline
\end{tabular}

For SBP and body weight, values are means \pm SE of $n$ animals. For fiber diameter and muscle weight/body weight, values are means \pm SE of $n$ fibers and $n$ muscles, respectively. Significant differences in fiber diameter $(F=7.3, \mathrm{df}=3,199, P<0.001)$ and muscle weight/body weight $(F=8$, $\mathrm{df}=3,44, P<0.001)$ are determined by analysis of variance.

${ }^{*} P<0.05$, significant difference in SBP and body weight between WKY and SHR by Student's $t$-test.

${ }^{\dagger} P<0.001$, significant difference in soleus muscle weight/body weight of SHR with respect to WKY by Bonferroni's $t$-test.

\section{Results}

\section{Animal Characteristics}

The average values of SBP for the SHR and WKY rats examined in this study, together with animal body and muscle weight, are summarized in Table 1 . SHR rats had SBP values approximately $46 \%$ higher than WKY rats. The body weight of SHR was $13 \%$ lower than WKY animals. As an index of muscle atrophy or hypertrophy, we determined the muscle mass expressed as muscle weight normalized to body weight. Atrophy was evident in the slow-twitch soleus muscle of SHR, with a significant $11 \%$ reduction of muscleto-body weight ratio with respect to WKY rats.

Furthermore, the diameter of muscle fibers was reduced, although not significantly, in the soleus muscle of SHR with respect to WKY rats (Table 1), thus supporting the evidence of muscular atrophy.

On the contrary, a tendency to hypertrophy was observed for EDL muscle, showing a not significant $4 \%$ and $15 \%$ increase of muscle-to-body weight ratio and fiber diameter, respectively, in SHR with respect to WKY animals (Table 1).

\section{Resting Cytosolic Calcium}

According to previous studies, ${ }^{17,36}$ resting $\left[\mathrm{Ca}^{2+}\right]_{\mathrm{i}}$ was significantly higher in soleus than in EDL muscles of normotensive WKY animals (Figure 1A). The resting $\left[\mathrm{Ca}^{2+}\right]_{\mathrm{i}}$ was significantly increased by $50 \%$ in EDL muscle and decreased by $30 \%$ in soleus muscle of SHR rats 

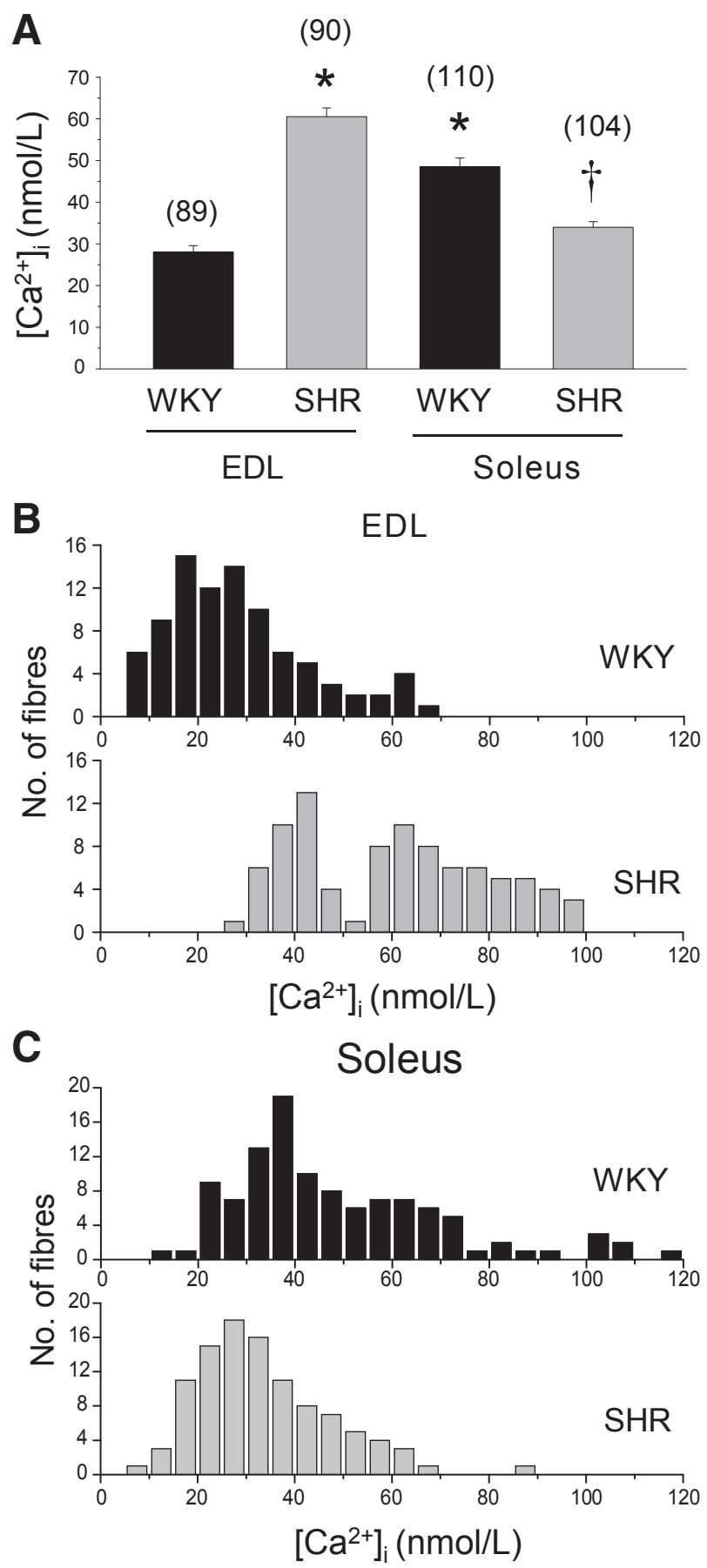

Figure 1 Resting calcium in EDL and soleus muscle from WKY and SHR animals. A: Data are given as means \pm SEM of resting $\left[\mathrm{Ca}^{2+}\right]_{i}$ measured in $n$ myofibers (indicated in parentheses) of at least five rats. $\mathbf{B}$ and $\mathbf{C}$ : Fiber distribution as a function of $\left[\mathrm{Ca}^{2+}\right]_{i}$ in rat muscles. Histograms were constructed using a sampling interval of $5 \mathrm{nmol} / \mathrm{L}$. Statistical analysis by analysis of variance shows significant differences $(F=86, \mathrm{df}=3,83, P<0.001)$. ${ }^{*} P<0.05$, significantly different by Bonferroni's $t$-test with respect to WKY EDL muscle; ${ }^{\dagger} P<0.05$, significantly different by Bonferroni's $t$-test with respect to WKY soleus muscle.

compared with WKY rats. To determine whether the changes of resting $\left[\mathrm{Ca}^{2+}\right]_{\mathrm{i}}$ were homogeneous within the whole EDL or soleus muscles, we plotted the distribution of single fibers as a function of $\left[\mathrm{Ca}^{2+}\right]_{i}$, using a sampling value of $5 \mathrm{nmol} / \mathrm{L}$ (Figure 1, B and C). In both EDL and soleus muscles of WKY rats, fibers are normally distributed around a mean value similar to the arithmetic mean reported in Figure 1A. Hypertension produced an opposite shift of the fiber distribution as a function of $\left[\mathrm{Ca}^{2+}\right]_{\mathrm{i}}$, for fast and slow muscles.

\section{Caffeine-Induced Calcium Release and RyR1 Expression}

To further analyze calcium-handling mechanisms specifically correlated to the SR properties in the different muscle groups, we investigated the response to caffeine, a modulator of the RyR, which generates a calcium transient by directly gating RyR. ${ }^{37}$ We determined the caffeine responsiveness at $40 \mathrm{mmol} / \mathrm{L}$ because the maximal amplitude value of caffeine-induced calcium transient in rat EDL and soleus intact muscle fibers was obtained at this dose. ${ }^{17}$ No significant reduction of the calcium transient after $40 \mathrm{mmol} / \mathrm{L}$ caffeine was observed in EDL muscle of SHR compared with WKY rats (Figure 2A). More important, the responsiveness to caffeine was significantly reduced (approximately 34\%) in SHR soleus muscle with respect to WKY.

To assess whether an alteration of RyR1 expression might account for the observed alteration of caffeine responsiveness, we measured the RyR1 protein level. In accordance with previous studies, ${ }^{34,38}$ the RyR1 level of WKY rats was lower in slow than in fast muscles, resulting in the expression of RyR1 approximately seven times higher in EDL compared with soleus muscle. No significant variation in RyR1 expression was observed in SHR muscles with respect to WKY (Figure 2, B and C).

\section{$\mathrm{Na}^{+} / \mathrm{Ca}^{2+}$ Exchanger Activity}

The $\mathrm{Na}^{+} / \mathrm{Ca}^{2+}$ exchanger (NCX) is a bidirectional transporter that can extrude $\mathrm{Ca}^{2+}$ from cell (forward mode) or bring $\mathrm{Ca}^{2+}$ into the cell (reverse mode), thus playing an important role in maintaining the intracellular $\mathrm{Ca}^{2+}$ homeostasis in skeletal muscle. ${ }^{39,40}$ To assess the contribution of the NCX in the alteration of calcium homeostasis observed in SHR muscles, we evaluated its activity in the reverse mode. According to previous studies, ${ }^{33,40,41}$ both in EDL and soleus muscle of WKY rats, the withdrawal of extracellular $\mathrm{Na}^{+}$was followed by an increase of approximately $10 \mathrm{nmol} / \mathrm{L}$ in $\left[\mathrm{Ca}^{2+}\right]_{\mathrm{i}}$ (Figure 3), reflecting the reverse NCX activity. Similarly, a $\mathrm{Na}^{+}$-free-induced $\left[\mathrm{Ca}^{2+}\right]_{\mathrm{i}}$ increase was observed in EDL and soleus muscle of SHR animals. These results demonstrate the existence of a functional NCX in skeletal muscle of both rat strains (Figure 3).

\section{Resting Sarcolemmal Cationic Permeability}

We used the $\mathrm{Mn}^{2+}$ quenching technique to assess the possibility that alteration of the resting calcium observed in EDL and soleus muscle of SHR animals could be related to 

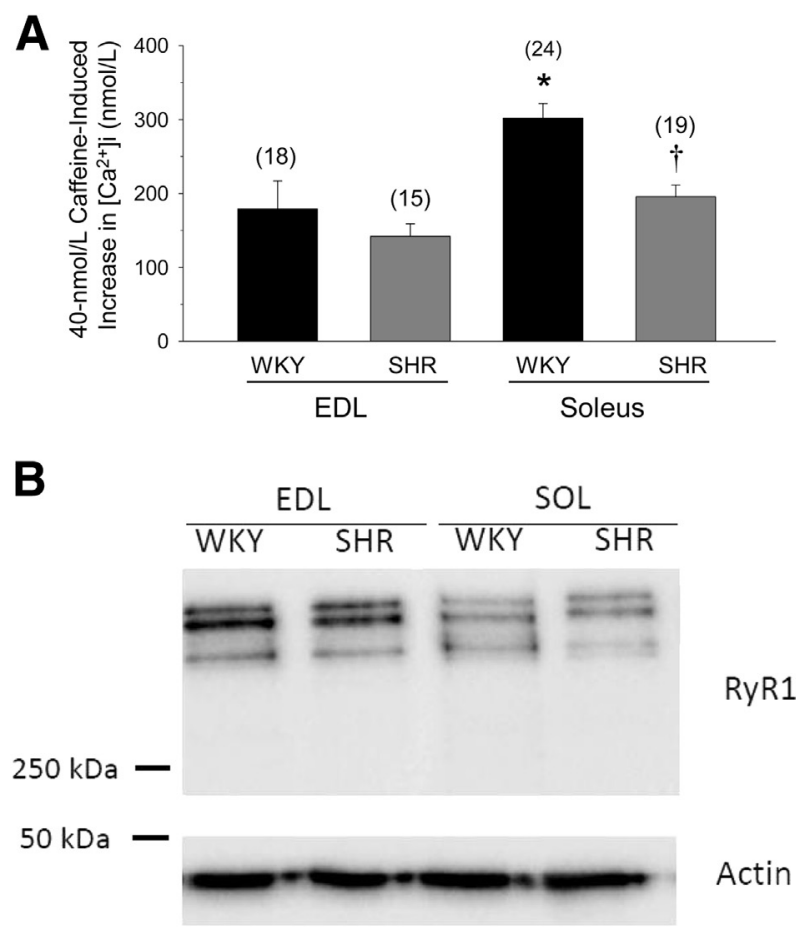

Actin

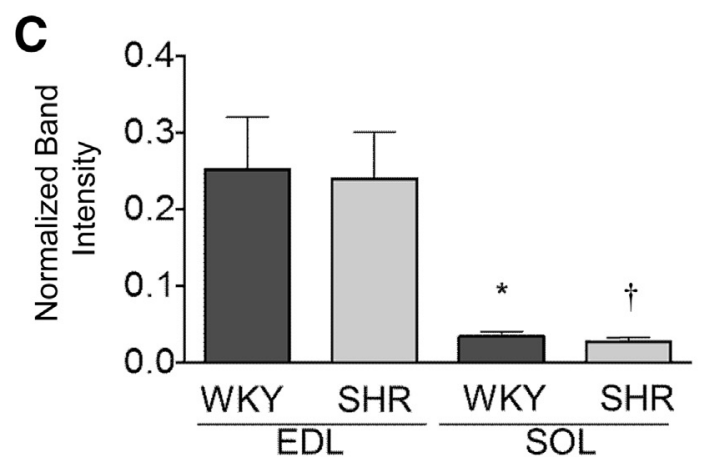

Figure 2 SR properties. A: Caffeine responsiveness. Amplitude values of calcium transiently recorded during application of $40 \mathrm{mmol} / \mathrm{L}$ caffeine. Data are given as means \pm SEM of calcium transiently measured in $n$ myofibers (indicated in parentheses) of at least five rats. Statistical analysis by analysis of variance shows significant differences $(F=8.7$, $\mathrm{df}=3,72, P<0.001)$. B: Western blot analysis of RyR1. Immunoblot of microsomal proteins with antibody against RyR1 of EDL and soleus (SOL) muscles from WKY and SHR animals. C: Each bar represents the quantification of the immunoblots normalized by actin of four rats. ${ }^{*} P<0.05$, significantly different by Bonferroni's $t$-test with respect to WKY EDL (A) or significantly different by $t$-test with respect to WKY EDL (C); ${ }^{\dagger} P<0.05$, significantly different by Bonferroni's $t$-test with respect to WKY soleus muscle $(\mathbf{A})$ or significantly different by $t$-test with respect to SHR EDL muscle (C).

changes in resting calcium influx. Consistent with previous studies, ${ }^{17,36}$ in normotensive WKY rats, the resting quench rate measured in soleus muscle was approximately 1.7 -fold that of EDL (Figure 4). In contrast to EDL muscle, where no modification of sarcolemmal permeability to divalent cations was observed between the two rat strains, the mean quench rate of SHR soleus muscle was significantly reduced by approximately $20 \%$ with respect to WKY soleus (Figure 4).

\section{SOCE Data}

SOCE is essential for maintenance of $\mathrm{Ca}^{2+}$ homeostasis by ensuring the SR refilling. ${ }^{19,31}$ Thus, a reduction of SOCE activity could account for the alteration of calcium homeostasis observed in hypertensive muscles. To test the functional status of SOCE in muscles of SHR animals, we used $\mathrm{Mn}^{2+}$ quenching of fura-2 fluorescence after SOCE activation. To this end, SR $\mathrm{Ca}^{2+}$ stores of muscle fibers were depleted with thapsigargin and caffeine. ${ }^{19,31}$ Hypertensive soleus muscle displayed a significantly diminished $\mathrm{Mn}^{2+}$ entry rate compared with that of normotensive muscle, indicating that SOCE induced by $\mathrm{SR} \mathrm{Ca}^{2+}$ depletion is compromised in SHR soleus muscle (Figure 5, A and B). In contrast, a slight SOCE increase was observed in EDL muscle of SHR with respect to EDL of WKY rats.

To perform a pharmacological characterization of the cation channels involved in the $\mathrm{Mn}^{2+}$ influx, we used $\mathrm{NiCl}_{2}$, a broad inhibitor of SOCE and of other $\mathrm{Ca}^{2+}$ entry mechanisms. ${ }^{23}$ On addition of $\mathrm{NiCl}_{2}$, the SOCE activity in EDL and soleus muscles of WKY animals was largely inhibited, producing a block of approximately $60 \%$ to $65 \%$ of quench rate after SOCE activation. For both muscle types, nickel block was not modified with hypertension (Figure 5C).

\section{Electrophysiological Measures of Muscle Excitability and Resting Ionic Conductances}

To verify the physiological relevance of the changes in calcium homeostasis observed in hypertensive skeletal muscle

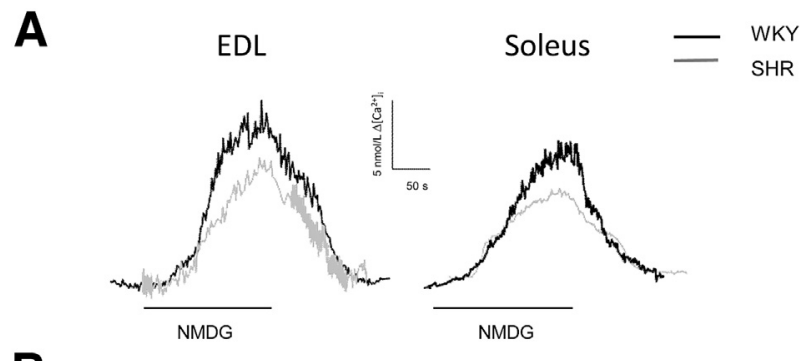

B

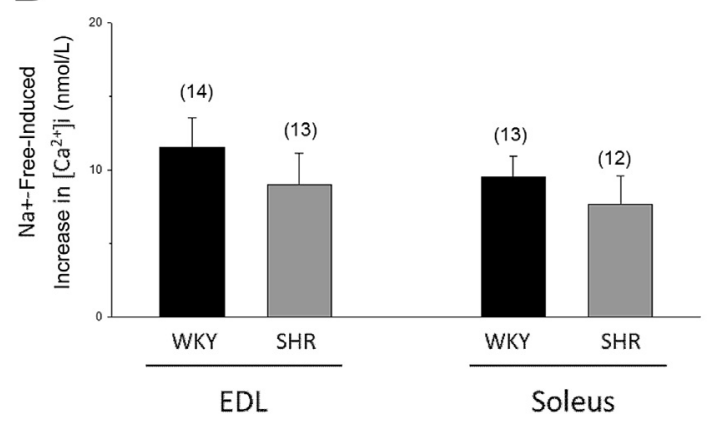

Figure $3 \mathrm{Na}^{+} / \mathrm{Ca}^{2+}$ exchange reverse mode activity. A: Representative traces of the $[\mathrm{Ca} 2+]_{i}$ increase observed after extracellular $\mathrm{Na}^{+}$removal [replaced by N-methyl-D-glucamine (NMDG)] from WKY and SHR muscle fibers. B: Data are given as means \pm SEM of calcium transiently measured in $n$ myofibers (indicated in parentheses) of four rats. Statistical analysis by analysis of variance shows no significant difference. 

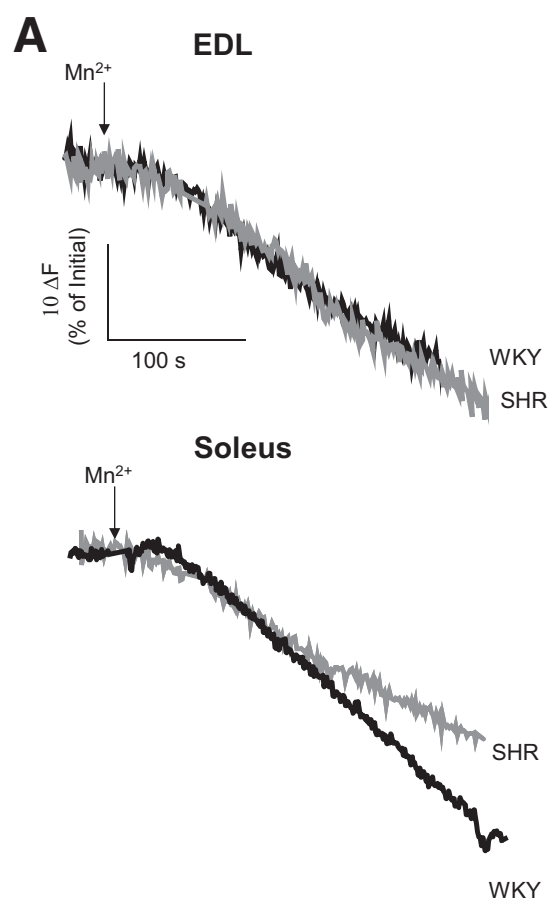

B

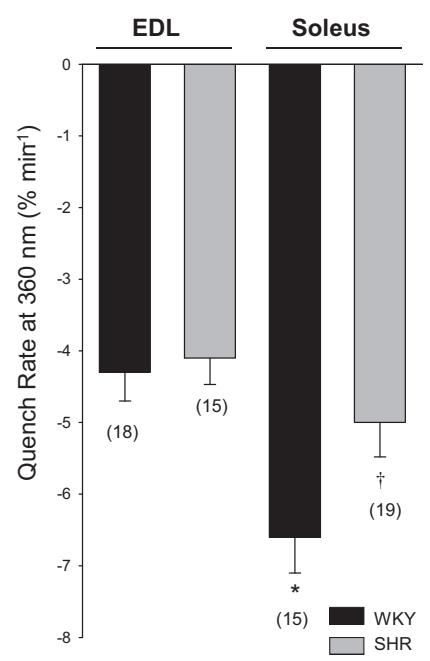

Figure 4 Sarcolemma resting calcium entry. A: Representative traces of $\mathrm{Mn}^{2+}$ quenching of fura-2 fluorescence at a 360-nm wavelength. Arrows designate perfusion of muscle fibers by $\mathrm{MnCl}_{2}$. Black trace is EDL fiber from WKY, and gray trace is from SHR; black trace is soleus fiber from WKY, and gray trace is from SHR. B: Mean quench rate. Data represent the means \pm SEM of quench rate measured in $n$ myofibers (indicated in parentheses) of at least four rats. Statistical analysis by analysis of variance shows significant differences $(F=5.9, \mathrm{df}=3,63, P<0.005) .{ }^{*} P<0.05$, significantly different by Bonferroni's $t$-test with respect to WKY $\mathrm{EDL} ;{ }^{\dagger} P<0.05$, significantly different by Bonferroni's $t$ test with respect to WKY soleus muscle. fibers, we evaluated membrane excitability in SHR muscles using the two intracellular microelectrodes technique (Table 2). Representative traces of the excitability pattern of SHR and WKY muscles are shown in Figure 6. According to a previous study, ${ }^{6}$ the resting membrane potential of SHR soleus fibers was more depolarized than that of the corresponding WKY muscle-type fibers. Furthermore, although no modification of the $\mathrm{I}_{\mathrm{th}}$ was seen in both SHR muscles, a significant decrease of the latency of the action potential was observed in SHR soleus muscle with respect to WKY animals (Table 2).
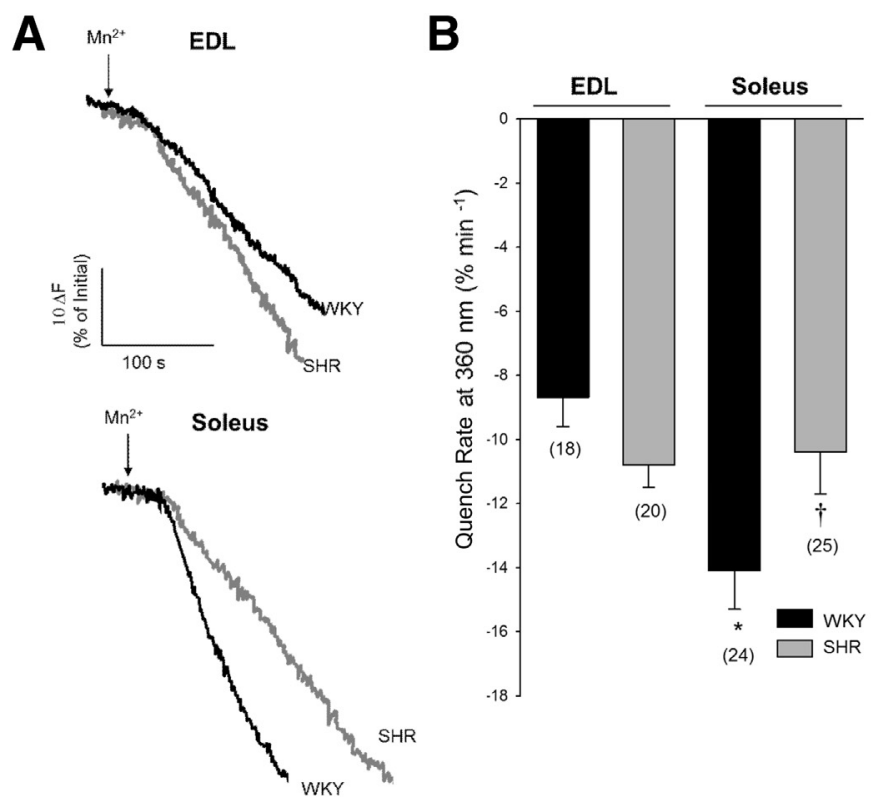

\section{C}

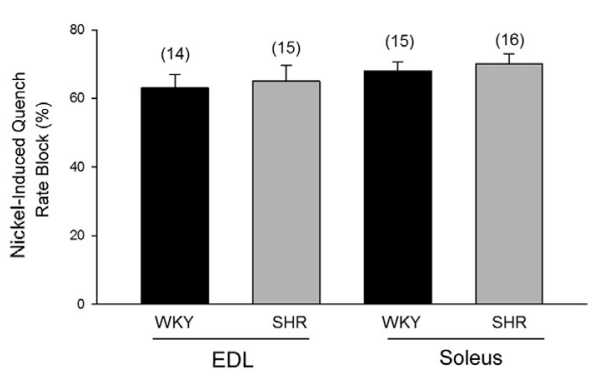

Figure 5 SOCE data. A: Representative traces of fura-2 fluorescence quench associated with $\mathrm{Mn}^{2+}$ influx in skeletal muscle fibers after depletion of SR $\mathrm{Ca}^{2+}$ stores induced by thapsigargin and caffeine (as described in Materials and Methods). Arrows designate perfusion of muscle fibers by $\mathrm{MnCl}_{2}$ after fiber treatment with thapsigargin/caffeine in zero calcium. Black trace is EDL fiber from WKY, and gray trace is from SHR; black trace is soleus fiber from WKY, and gray trace is from SHR. B: Mean quench rate after SOCE activation. Data are given as means \pm SEM of quench rate measured in $n$ myofibers (indicated in parentheses) of at least four rats. Statistical analysis by analysis of variance shows significant differences $(F=4, \mathrm{df}=3,83, P<0.02)$. C: Pharmacological characterization of SOCE. Effect of $2 \mathrm{mmol} / \mathrm{L} \mathrm{NiCl}_{2}$ on SOCE. Results are expressed as percentage of quench rate change induced by nickel in respect to quench rate value calculated before nickel application after SOCE activation. Data are given as means \pm SEM of quench rate percentage block measured in $n$ myofibers (indicated in parentheses) of at least four rats. Statistical analysis by analysis of variance showed no significant difference. ${ }^{*} P<0.05$, significantly different by Bonferroni's $t$-test with respect to $\mathrm{WKY} \mathrm{EDL}^{\dagger} P<0.05$, significantly different by Bonferroni's $t$-test with respect to WKY soleus muscle (B). 
Table 2 Membrane Excitability Parameters

\begin{tabular}{ccccc}
\hline Variable & $\begin{array}{l}\text { No. of } \\
\text { fibers }\end{array}$ & $\mathrm{I}_{\text {th }}(\mathrm{nA})$ & $\begin{array}{l}\text { Lat } \\
\text { (milliseconds) }\end{array}$ & RMP $(\mathrm{mV})$ \\
\hline EDL & & & & \\
WKY & 14 & $179 \pm 17$ & $8.9 \pm 1.4$ & $-72 \pm 3$ \\
SHR & 16 & $171 \pm 15$ & $9.5 \pm 0.13$ & $-70 \pm 2$ \\
$\begin{array}{c}\text { Soleus } \\
\text { WKY }\end{array}$ & 15 & $129 \pm 13$ & $11.7 \pm 1.05$ & $-69 \pm 0.3$ \\
SHR & 16 & $122 \pm 5.8$ & $9.03 \pm 0.7^{*}$ & $-64 \pm 2.4$ \\
\hline
\end{tabular}

Columns from left to right indicate the means \pm SEM of $I_{\text {th }}$ (threshold current) and RMP, calculated from $n$ fibers. Statistical analysis by analysis of variance showed significant differences $(F=2, \mathrm{df}=3,57)$.

$* P<0.05$, significantly different by Bonferroni's $t$-test with respect to WKY soleus muscle.

Lat, latency of action potential; RMP, resting membrane potential.

Because resting $\mathrm{gCl}$ is an electrical parameter that controls the electrical stability of sarcolemma and can be affected by calcium homeostasis variation, we also measured this parameter in muscle fibers. According to previous studies, ${ }^{42}$ in normotensive $\mathrm{WKY}$ rats, the $\mathrm{gCl}$ resulted approximately 1.7 times higher in the fast-twitch EDL muscle with respect to the slow-twitch soleus muscle (Table 3). Consistent with the shorter latency of action potential observed in SHR soleus, a significant $16 \%$ increase of $\mathrm{gCl}$ was observed in hypertensive soleus compared with WKY soleus muscle. On the other hand, the $\mathrm{gCl}$ was not modified by hypertension in EDL muscle, with the $\mathrm{gCl}$ values being similar in the two rat strains. Furthermore, the value of the macroscopic gK was only slightly, and not significantly, lower in both EDL and soleus muscles of SHR animals with respect to the relative WKY muscle type. The variation of the gm was consistent with $\mathrm{gK}$ and $\mathrm{gCl}$ modifications (Table 3 ).

\section{Gene Expression Analyses}

To determine whether hypertension could produce adaptive or compensative effects on the expression of some proteins

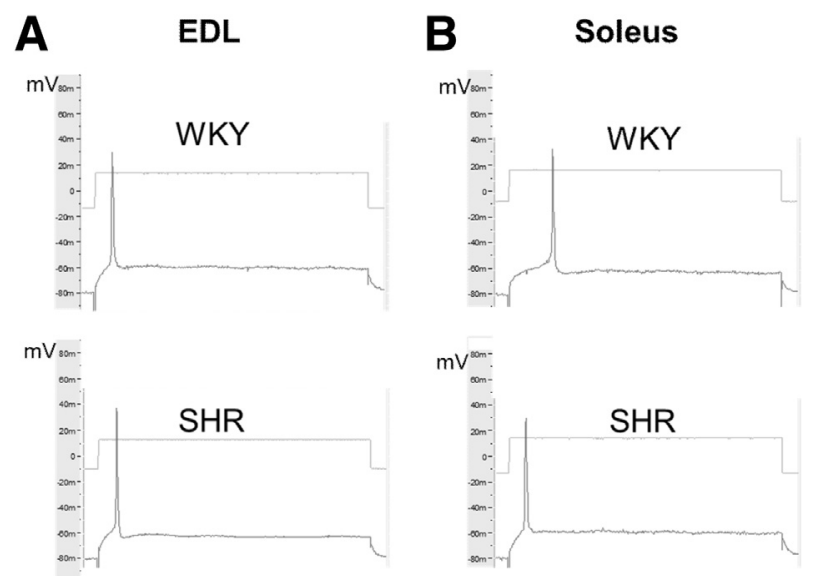

Figure 6 Excitability characteristics. Representative intracellular microelectrode recordings of excitability characteristics in EDL (A) and soleus (B) muscle fibers of SHR and WKY rats. Excitability parameters (reported in Table 2) were measured in at least 15 fibers from at least three animals for each rat strain.
Table 3 Component Ionic Conductances

\begin{tabular}{llll}
\hline Variable & $\mathrm{gm}\left(\mu \mathrm{S} / \mathrm{cm}^{2}\right)$ & $\mathrm{gCl}\left(\mu \mathrm{S} / \mathrm{cm}^{2}\right)$ & $\mathrm{gK}\left(\mu \mathrm{S} / \mathrm{cm}^{2}\right)$ \\
\hline EDL & & & \\
WKY & $2540 \pm 58$ & $2205 \pm 42$ & $335 \pm 17$ \\
SHR & $2560 \pm 106$ & $2288 \pm 78$ & $272 \pm 35$ \\
Soleus & & & \\
WKY & $1701 \pm 58$ & $1346 \pm 40^{*}$ & $354 \pm 22$ \\
SHR & $1793 \pm 91$ & $1560 \pm 61^{\dagger}$ & $292 \pm 18$ \\
\hline
\end{tabular}

Each value represents the means \pm SEM of component ionic conductances measured in 27 to 62 myofibers of at least four rats. Statistical analysis by analysis of variance showed significant differences $(F=63$, $\mathrm{df}=3,155, P<0.001)$.

${ }^{*} P<0.05$, significantly different by Bonferroni's $t$-test with respect to WKY EDL muscle.

${ }^{\dagger} P<0.05$, significantly different by Bonferroni's $t$-test with respect to WKY soleus muscle.

S, Siemens.

associated with calcium homeostasis, we used qPCR to quantify mRNA levels of a selected panel of genes encoding for proteins responsible for the calcium-dependent parameters described herein. As far as the SOCE machinery components were concerned, we focused our attention on the stromal interaction molecule (STIMI) and its main target, the calcium release-activated calcium modulator 1 (Orail). ${ }^{43,44}$ Because the transient receptor potential canonical (TRPC) family of calcium-permeable channels has been proposed to contribute to SOCE,${ }^{45-47}$ we also determined the expression of TRPCl. In addition, we measured the expression of other calcium-handling proteins involved in the structural organization of the triad located in close proximity to the SR and plasma membrane SOCE in skeletal muscle, ${ }^{48}$ such as junctophilins 1 and 2 ( $\mathrm{JPHI}$ and $\mathrm{JPH} 2$ ), $R y R l$, voltage-sensitive calcium channel Cav1.1 (CACN1S or $D H P R)$, and sarcoplasmic/endoplasmic reticulum $\mathrm{Ca}^{2+}$. ATPase $\alpha 2$ (ATP2Al). The shifts in the mRNA levels of the selected genes of SHR muscles with respect to WKY

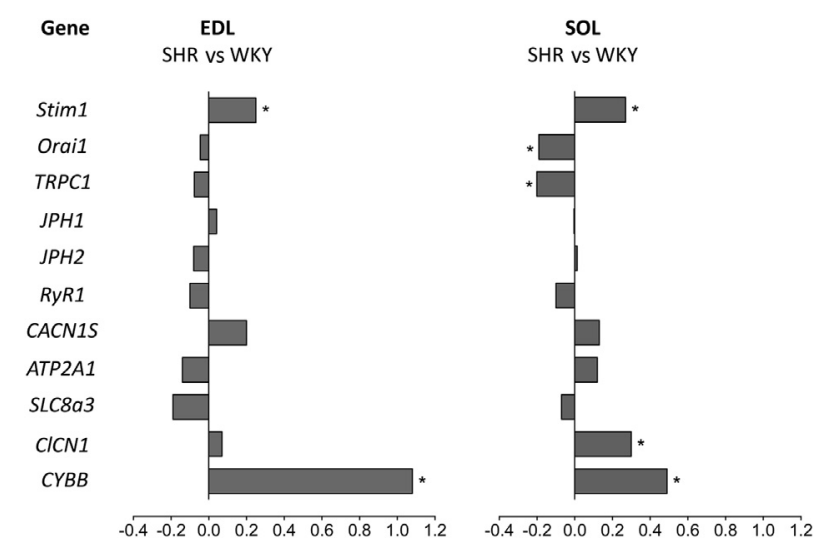

Figure 7 Variations in gene expression in EDL and soleus ( $\mathrm{SOL}$ ) muscles induced by hypertension. Transcript levels were determined by real-time PCR for the selected genes. The number of the abscissa indicates the fold change in gene expression normalized for housekeeping gene. For each gene, transcript levels were determined in EDL and soleus muscles of at least nine animals for each rat strain. ${ }^{*} P<0.05$ (at least), significant fold changes, according to two-tailed unpaired Student's $t$-test. 
muscles are shown in Figure 7. Interestingly, some variations in the expression of specific genes were noteworthy in both EDL and soleus muscles. Particularly, SHR EDL muscles showed a significant increase of STIM1 expression, whereas SHR soleus muscles exhibited a significant increase of STIM1 expression paralleled with a significant decrease of Orai1 and TRPC 1 mRNAs.

We also determined the expression of NCX3 (SLC8A3), the isoform within the $S L C 8$ gene family predominantly expressed in skeletal muscle. ${ }^{49}$ In accordance with previous studies, ${ }^{49,50}$ in normotensive WKY animals, SLC8A3 was highly expressed in fast-twitch EDL muscle with respect to slow-twitch soleus muscle (Supplemental Figure S1). No significant change was observed in both SHR EDL and soleus muscles with respect to the relative WKY muscles, except for a trend of down-regulation (Figure 7).

Furthermore, consistent with the $\mathrm{gCl}$ value, the expression of CLC-1 chloride channel ( $C L C N I)$, which is the main contributor to $\mathrm{gCl}$, was increased in SHR soleus with respect to WKY soleus muscle.

Finally, as a marker of the oxidative stress, we determined the expression of the NADPH oxidase catalytic subunit gp91 ${ }^{\text {phox }}$, also called Nox $2(C Y B B)$. The expression of CYBB was increased in both muscles of SHR with respect to WKY animals, more markedly in EDL muscle (Figure 7).

\section{Discussion}

It is well recognized that both in animal models and in humans, cardiovascular diseases are often associated with distinct skeletal muscle alterations regarding function and metabolism. ${ }^{2,3,51}$ In EDL and soleus of SHR animals, a series of muscle alterations were found, indicating a form of mild myopathy. ${ }^{6,7,11,14}$ Herein, we demonstrated that hypertension causes a phenotype-dependent dysregulation of skeletal muscle calcium homeostasis.

\section{Hypertension-Induced Alterations of Resting $\left[\mathrm{Ca}^{2+}\right]_{i}$}

Our results showed that some atrophy or hypertrophy indexes, such as muscle weight and muscle fiber diameter, as well as the resting $\left[\mathrm{Ca}^{2+}\right]_{i}$ are differently affected by hypertension in slow-twitch muscle with respect to fast-twitch muscle. Particularly, muscle atrophy was evident in soleus and a tendency to hypertrophy was observed in EDL, whereas the resting $\left[\mathrm{Ca}^{2+}\right]_{\mathrm{i}}$ was altered in the two muscle types in the opposite direction. In hypertensive animals, the resting $\left[\mathrm{Ca}^{2+}\right]_{i}$ of soleus muscle was reduced by $30 \%$, whereas the resting $\left[\mathrm{Ca}^{2+}\right]_{\mathrm{i}}$ of EDL muscle was increased by $50 \%$. Alternately, the resting $\left[\mathrm{Ca}^{2+}\right]_{\mathrm{i}}$ of SHR soleus and EDL muscles was highly similar to WKY EDL and WKY soleus, respectively. These hypertension-induced alterations of the resting $\left[\mathrm{Ca}^{2+}\right]_{\mathrm{i}}$ could be in strict correlation with the fiber phenotype transition reported in both muscles of SHR animals. Indeed, in SHR animals, EDL muscle showed a reduction of type IIB fast fibers, whereas soleus muscle yielded a lower proportion of type I fibers and a higher proportion of fast-twitch and hybrid fibers, in comparison with the WKY strain. ${ }^{7,13,14}$

\section{Hypertension-Induced Alteration of SR Calcium Signaling}

Muscle cytosolic calcium alteration may result from dysfunction in the calcium handling mechanisms involved in the regulation of internal stores. We introduced the RyR activator caffeine to deplete $\mathrm{Ca}^{2+}$ from SR, the main internal calcium store. Although caffeine-induced calcium transients were not significantly different in EDL muscles of the two rat strains, soleus muscles of hypertensive animals had significantly lower caffeine-induced calcium transient amplitude in comparison with WKY rats. The lack of significant hypertension-induced effects on soleus RyR1 expression at the gene and protein levels led us to hypothesize that the transiently reduced caffeine could be likely due to a decreased $\mathrm{Ca}^{2+}$ storage capacity of soleus SR in SHR. However, because hypertension is a pathological state characterized by significantly increased oxidative stress, as also indicated by the enhanced expression of the NADPH oxidase catalytic subunit gp91 ${ }^{\text {phox }}$ in both SHR muscles, we cannot exclude the possibility that RyR1 post-translational modifications, such as oxidation, nitrosylation, or phosphorylation, ${ }^{52,53}$ could take place in SHR muscle, thus accounting for the observed $\mathrm{Ca}^{2+}$ dysregulation. Further studies are needed to assess this aspect.

\section{Hypertension-Induced Alterations of Sarcolemmal Permeability to Calcium Ions}

Alteration of $\left[\mathrm{Ca}^{2+}\right]_{i}$ could be sustained by a change of calcium influx through the sarcolemmal membrane. NCX is the main actor among the mechanisms involved in the regulation of calcium through the sarcolemma. We demonstrated the existence of a functional NCX in reverse mode in skeletal muscle of both rat strains. These results, together with no significant alteration of NCX3 gene expression, led us to conclude that NCX is not primarily involved in the observed calcium homeostasis alteration. However, additional experiments are required to assess the activity of NCX in forward mode, for a wider analysis of the role of this exchanger in hypertensive skeletal muscle.

By using the manganese-quenching technique, we also determined calcium entry both at rest and after SOCE activation. In contrast to EDL muscle, showing similar calcium entry in both rat strains, in soleus muscle of SHR, we found a reduction of the cation membrane permeability at rest, an effect that resulted more marked in condition of SOCE activation. Muscle fibers were exposed to $\mathrm{NiCl}_{2}$, which proved to be equally effective in reducing $\mathrm{Ca}^{2+}$ entry after SOCE activation in both rat strains. The fact that a 

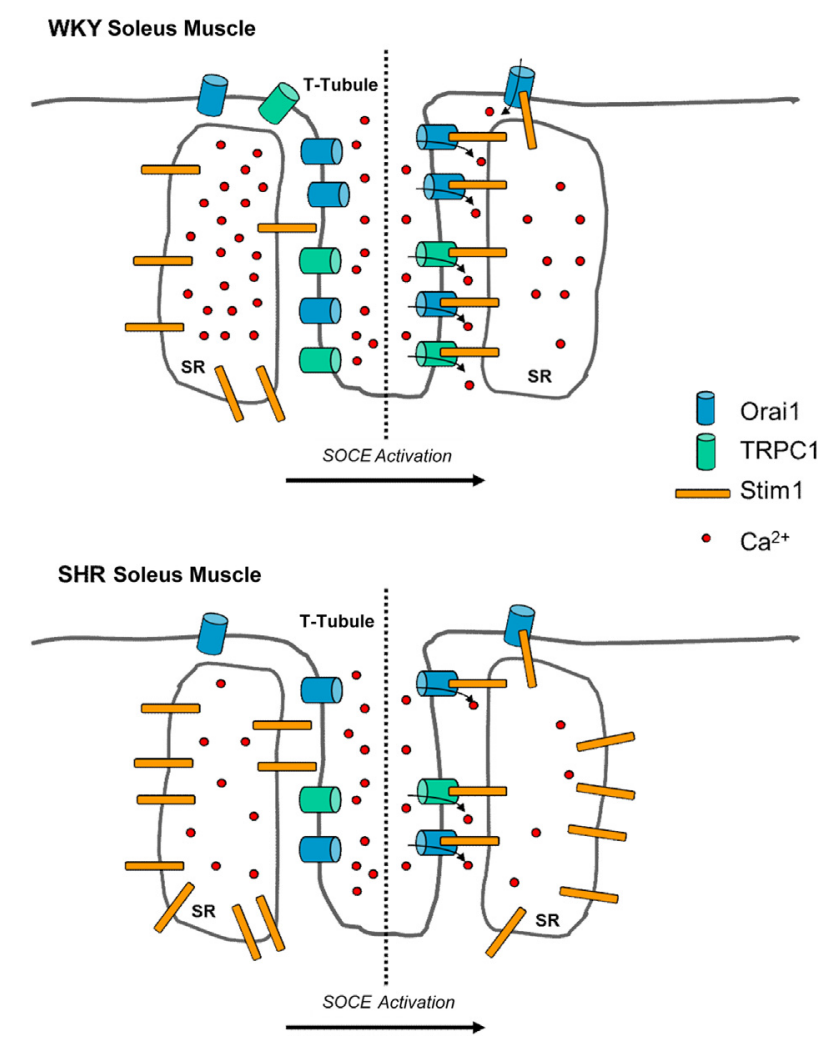

Figure 8 Schematic representation of the effect of hypertension on SOCE of SHR soleus muscle. Data regarding gene analysis and caffeine responsiveness showed that soleus muscle fibers of SHR animals are characterized by an increased expression of STIM1 accompanied by a significant decrease of the expression of both Orai1 and TRPC1 and by a decreased SR $\mathrm{Ca}^{2+}$ storage capacity. Thus, we propose that after SOCE activation (ie, after SR $\mathrm{Ca}^{2+}$ stores depletion by thapsigargin and caffeine), the sarcolemma $\mathrm{Ca}^{2+}$ entry is reduced in SHR soleus with respect to WKY soleus muscle due to a reduced aggregation between STIM1 and $\mathrm{Ca}^{2+}$ channels (Orai1 and TRPC1).

similar nickel-induced block was observed independently on the muscle type and genotype suggests that no qualitative difference, rather than a quantitative modification in ion channels involved in the calcium influx, could take place in SHR soleus muscle. Consistent with these findings, we found a significant alteration of the expression levels of STIM1, Orai1, and TRPC1. Indeed, although an increased expression of STIM1 without modification of Orai1 and TRPC1 was found in EDL muscle, in soleus muscle, the increased expression of STIM1 was accompanied by a significant decrease of the expression of both Orail and TRPC1. We conclude that the down-regulation of Orai1, the main target channel of STIM1, 4,45 and TRPC1, another proposed target of STIM1, ${ }^{4-47}$ causes a reduced SOCE function in SHR soleus muscle (Figure 8).

All these findings regarding the SOCE process may be of significant physiopathological importance. SOCE is a pivotal mechanism linking extracellular calcium entry and intracellular $\mathrm{Ca}^{2+}$ storage, especially during the repetitive cycles of E-C coupling when the maintenance of SR $\mathrm{Ca}^{2+}$ store critically needs the activation of SOCE. Indeed, SOCE is fundamental for store repletion, limiting fatigue under conditions of extensive exercise, ${ }^{19}$ and dysregulation of such $\mathrm{Ca}^{2+}$ entry mechanism may lead to severe muscle pathological conditions. ${ }^{54,55}$ The reduction of caffeine-induced calcium transient amplitude that we observed in soleus SHR muscle could be attributed to an SOCE reduction that could directly modulate $\mathrm{Ca}^{2+}$ storage, leading to compromised SR $\mathrm{Ca}^{2+}$ release. Thus, the compromised SOCE described herein could be linked to the reduced contractile force and decreased fatigue resistance observed in soleus muscle of hypertensive animals. ${ }^{6,56-59}$ Indeed, we postulate that a chronically compromised SOCE may lead to an equally chronic reduction in the amount of $\mathrm{Ca}^{2+}$ stored in the SR. Consequently, less $\mathrm{Ca}^{2+}$ will be available and released and, finally, less force will be produced.

\section{The Alteration of Hypertension-Induced Calcium Homeostasis Influences Some Muscle Functional Outcomes}

As functional indexes of potential muscle impairment due to the alteration of hypertension-induced calcium homeostasis, we evaluated muscle excitability and resting $\mathrm{gCl}$, the electrical parameter sustained by the voltage-gated chloride channel CLC-1, which is negatively regulated by the $\mathrm{Ca}^{2+}$. dependent protein kinase $\mathrm{C}$ and is critical for the maintenance of membrane stability. ${ }^{60,61}$ Interestingly, SHR soleus, the muscle in which calcium homeostasis undergoes deeper changes in terms of alteration of resting $\left[\mathrm{Ca}^{2+}\right]_{\mathrm{i}}$ and SOCE mechanism, seemed to be the most affected muscle at the functional level. Indeed, resting $\mathrm{gCl}$ is significantly increased in SHR soleus muscle with respect to WKY. Such an effect determines a modification of the sarcolemma excitability in soleus muscle fibers. Remarkably, the alteration of the latency of action potential may contribute to the impaired resistance to fatigue observed in hypertension. ${ }^{4,56,58}$ The fact that the $\mathrm{gCl}$ increase in SHR soleus muscle was in parallel with an enhancement of CLCN1 gene expression could indicate that the alteration of calcium homeostasis can interfere with CLC-1 function, likely through protein kinase $\mathrm{C}$ regulation and through an alteration of the activity of transcriptional factor pathways. Further studies are needed to investigate the specific pathways involved.

\section{Conclusions}

Herein, we demonstrated that hypertension caused a phenotype-dependent calcium homeostasis dysregulation in skeletal muscle. The soleus muscle is basically an antigravity and posture muscle that is persistently active and, consequently, more sensitive to changes of muscle activity and loading levels as well as of blood supply. Because soleus is an oxidative muscle, it can be hypothesized that this muscle is more affected by hypertension because it is more sensible to the reduction in blood flow secondary to vascular 
changes. A similar mechanism has been reported for soleus muscle in disuse. ${ }^{62}$ Furthermore, differences between EDL and soleus muscle in sensing hypertension could also suggest that fast- and slow-twitch muscles could differently counteract the hypertensive stimuli by muscle-type specific compensative responses. Interestingly, it has been recently demonstrated that the skeletal muscle alterations observed in autophagy markers between WKY and SHR appeared to be muscle-type specific, with a larger increase detected in fast skeletal muscles. ${ }^{15}$ Because DNA fragmentation and caspase-3 activity were elevated to a greater extent in slow versus fast skeletal muscle of SHR animals, ${ }^{11}$ it has been proposed that autophagy protects fast skeletal muscle from excess apoptotic signaling during hypertension. This could also justify the tendency to hypertrophy that we observed in EDL muscle of SHR. Therefore, we can hypothesize that the differential autophagic activity between muscle types in hypertensive animals could ultimately influence apoptosis and other cellular processes regarding calcium homeostasis.

Whether the observed calcium dysregulation in hypertensive muscles is primarily due to an alteration in gene expression in muscle fibers or rather due to the higher blood pressure in the arterioles in muscle is an open question. We used SHR animals with established hypertension; thus, we strongly support the idea that the higher blood pressure is the cause of the observed calcium homeostasis alteration. It is well known that in hypertension, skeletal muscles undergo a series of alterations regarding both function and metabolism, likely related to changes in gene expression. ${ }^{56-59,63}$ However, assessing the precise sequence of events responsible for the hypertension-induced alterations is difficult. Indeed, it is still controversial whether the altered gene expression is a cause or a result of blood pressure elevation; similar to humans, the hemodynamic and metabolic disturbances in the SHR are also multifactorially determined. ${ }^{63}$ It would be desirable to see whether the changes we reported are also seen in the aged-matched hypertensive animals, and occur with the onset of hypertension. Further investigations using prehypertensive and aged hypertensive rats, with or without antihypertensive drug treatment, will allow assessment of this issue.

The alteration of $\left[\mathrm{Ca}^{2+}\right]_{\mathrm{i}}$ and SOCE in SHR skeletal muscles supports the idea that the modification of calcium homeostasis may indeed contribute to the muscle functional and metabolic phenotype observed in SHR animals. Because calcium ions exert a crucial role in muscle function and in safeguarding muscle integrity, the alteration of resting calcium levels reported herein may be particularly significant for the development of the muscle weakness frequently observed in hypertensive patients. As shown for aging, SOCE should be seen as an important functional biomarker of muscle function also in hypertension, and it may provide a suitable target for therapeutic intervention for counterbalancing muscle performance decline.

Moreover, measurement of the calcium-dependent parameters determined herein could help to predict which of the various classes of antihypertensive drugs could alter muscle performance. Finally, skeletal muscle is considered as a secretary organ capable of producing and releasing myokines, which work in a hormone-like manner and exert specific endocrine effects on distant organs, generating muscleliver and muscle-adipose tissue cross talk. ${ }^{64}$ Interestingly, it has been more recently proposed that musclin, a skeletal muscle-derived secretory factor, is involved in blood pressure regulation. ${ }^{65}$ It could be hypothesized that alteration of muscle calcium signaling could lead to an altered myokine secretion or response. SOCE is known to be essential for driving nuclear translocation and activity of various transcription factors, including c-fos and nuclear factor of activated $\mathrm{T}$ cells. ${ }^{66}$ Therefore, our findings could contribute to clarify the molecular mechanism involved in pathological processes of hypertension-associated diseases, such as obesity and type 2 diabetes mellitus.

\section{Acknowledgments}

We thank Drs. Monica Montagnani and Maria Assunta Potenza for performing blood pressure measurements and Prof. Jean-Francois Desaphy for suggestions and comments during the experimental work.

A.L. and D.C.C. designed research; A.L., G.M.C., A.S., S.P., M.C., M.D.B., and E.C. performed research; A.L., G.M.C., A.S., S.P., M.D.B., E.C., B.F., and D.T. analyzed data; and A.L., G.M.C., and D.C.C. wrote the paper.

\section{Supplemental Data}

Supplemental material for this article can be found at http://dx.doi.org/10.1016/j.ajpath.2014.06.020.

\section{References}

1. Frisk-Holmberg M, Essén B, Fredrikson M, Ström G, Wibell L: Muscle fibre composition in relation to blood pressure response to isometric exercise in normotensive and hypertensive subjects. Acta Med Scand 1983, 213:21-26

2. Harridge SD, Magnusson G, Gordon A: Skeletal muscle contractile characteristics and fatigue resistance in patients with chronic heart failure. Eur Heart J 1996, 17:896-901

3. Hedman A, Reneland R, Lithell HO: Alterations in skeletal muscle morphology in glucose-tolerant elderly hypertensive men: relationship to development of hypertension and heart rate. J Hypertens 2000, 18:559-565

4. Paiardi S, Rodella LF, De Ciuceis C, Porteri E, Boari GE, Rezzani R, Rizzardi N, Platto C, Tiberio GA, Giulini SM, Rizzoni D, AgabitiRosei E: Immunohistochemical evaluation of microvascular rarefaction in hypertensive humans and in spontaneously hypertensive rats. Clin Hemorheol Microcirc 2009, 42:259-268

5. Brunel P, Baschiera F, Cifková R: Exercise testing in hypertensive patients for assessing the cardiovascular protective potential of antihypertensive drugs. Ther Adv Cardiovasc Dis 2013, 7:99-108

6. Atrakchi A, Gray SD, Carlsen RC: Development of soleus muscles in SHR: relationship of muscle deficits to rise in blood pressure. Am J Physiol 1994, 267:C827-C835 
7. Hernández N, Torres SH, Losada M, Finol HJ: Morphological alterations in skeletal muscle of spontaneously hypertensive rats. Invest Clin 2008, 49:79-91

8. Pickar JG, Carlsen RC, Atrakchi A, Gray SD: Increased $\mathrm{Na}(+)-\mathrm{K}+$ pump number and decreased pump activity in soleus muscles in SHR. Am J Physiol 1994, 267:C836-C844

9. Zecchin HG, Bezerra RM, Carvalheira JB, Carvalho-Filho MA, Metze K, Franchini KG, Saad MJ: Insulin signalling pathways in aorta and muscle from two animal models of insulin resistance: the obese middle-aged and the spontaneously hypertensive rats. Diabetologia 2003, 46:479-491

10. Kobayashi N, DeLano FA, Schmid-Schönbein GW: Oxidative stress promotes endothelial cell apoptosis and loss of microvessels in the spontaneously hypertensive rats. Arterioscler Thromb Vasc Biol 2005, 25:2114-2121

11. Quadrilatero J, Rush JW: Evidence for a pro-apoptotic phenotype in skeletal muscle of hypertensive rats. Biochem Biophys Res Commun 2008, 368:168-174

12. McMillan EM, Graham DA, Rush JW, Quadrilatero J: Decreased DNA fragmentation and apoptotic signaling in soleus muscle of hypertensive rats following 6 weeks of treadmill training. J Appl Physiol 2012, 113:1048-1057

13. Ben Bachir-Lamrini L, Sempore B, Mayet MH, Favier RJ: Evidence of a slow-to-fast fiber type transition in skeletal muscle from spontaneously hypertensive rats. Am J Physiol 1990, 258:R352-R357

14. Bortolotto SK, Stephenson DG, Stephenson GM: Fiber type populations and $\mathrm{Ca} 2+$-activation properties of single fibers in soleus muscles from SHR and WKY rats. Am J Physiol 1999, 276: C628-C637

15. Bloemberg D, McDonald E, Dulay D, Quadrilatero J: Autophagy is altered in skeletal and cardiac muscle of spontaneously hypertensive rats. Acta Physiol (Oxf) 2014, 210:381-391

16. Berchtold MW, Brinkmeier H, Müntener M: Calcium ion in skeletal muscle: its crucial role for muscle function, plasticity, and disease. Physiol Rev 2000, 80:1215-1265

17. Fraysse B, Desaphy JF, Pierno S, De Luca A, Liantonio A, Mitolo CI, Camerino DC: Decrease in resting calcium and calcium entry associated with slow-to-fast transition in unloaded rat soleus muscle. FASEB J 2003, 17:1916-1918

18. Desaphy JF, Pierno S, Liantonio A, Giannuzzi V, Digennaro C, Dinardo MM, Camerino GM, Ricciuti P, Brocca L, Pellegrino MA, Bottinelli R, Camerino DC: Antioxidant treatment of hindlimbunloaded mouse counteracts fiber type transition but not atrophy of disused muscles. Pharmacol Res 2010, 61:553-563

19. Kurebayashi N, Ogawa Y: Depletion of $\mathrm{Ca} 2+$ in the sarcoplasmic reticulum stimulates $\mathrm{Ca} 2+$ entry into mouse skeletal muscle fibres. J Physiol 2001, 533:185-199

20. Stiber JA, Rosenberg PB: The role of store-operated calcium influx in skeletal muscle signaling. Cell Calcium 2011, 49:341-349

21. Edwards JN, Friedrich O, Cully TR, von Wegner F, Murphy RM, Launikonis BS: Upregulation of store-operated $\mathrm{Ca} 2+$ entry in dystrophic mdx mouse muscle. Am J Physiol Cell Physiol 2010, 299: C42-C50

22. Zhao X, Moloughney JG, Zhang S, Komazaki S, Weisleder N: Orai1 mediates exacerbated $\mathrm{Ca}(2+)$ entry in dystrophic skeletal muscle. PLoS One 2012, 7:e49862

23. Zhao X, Weisleder N, Thornton A, Oppong Y, Campbell R, Ma J, Brotto M: Compromised store-operated $\mathrm{Ca} 2+$ entry in aged skeletal muscle. Aging Cell 2008, 7:561-568

24. Pedersen TH, de Paoli F, Nielsen OB: Increased excitability of acidified skeletal muscle: role of chloride conductance. J Gen Physiol 2005, 125:237-246

25. Pierno S, Tricarico D, Liantonio A, Mele A, Digennaro C, Rolland JF, Bianco G, Villanova L, Merendino A, Camerino GM, De Luca A, Desaphy JF, Camerino DC: An olive oil-derived antioxidant mixture ameliorates the age-related decline of skeletal muscle function. Age (Dordr) 2014, 36:73-88
26. Potenza MA, Gagliardi S, De Benedictis L, Zigrino A, Tiravanti E, Colantuono G, Federici A, Lorusso L, Benagiano V, Quon MJ, Montagnani M: Treatment of spontaneously hypertensive rats with rosiglitazone ameliorates cardiovascular pathophysiology via antioxidant mechanisms in the vasculature. Am J Physiol Endocrinol Metab 2009, 297:E685-E694

27. Liantonio A, Gramegna G, Camerino GM, Dinardo MM, Scaramuzzi A, Potenza MA, Montagnani M, Procino G, Lasorsa DR, Mastrofrancesco L, Laghezza A, Fracchiolla G, Loiodice F, Perrone MG, Lopedota A, Conte S, Penza R, Valenti G, Svelto M, Camerino DC: In-vivo administration of CLC-K kidney chloride channels inhibitors increases water diuresis in rats: a new drug target for hypertension? J Hypertens 2012, 30:153-167

28. Fraysse B, Liantonio A, Cetrone M, Burdi R, Pierno S, Frigeri A, Pisoni M, Camerino C, De Luca A: The alteration of calcium homeostasis in adult dystrophic mdx muscle fibers is worsened by a chronic exercise in vivo. Neurobiol Dis 2004, 17:144-154

29. Grynkiewicz G, Poenie M, Tsien RY: A new generation of $\mathrm{Ca}^{2+}$ indicators with greatly improved fluorescence properties. J Biol Chem 1985, 260:3440-3450

30. Parekh AB, Penner R: Store depletion and calcium influx. Physiol Rev 1997, 77:901-930

31. Zhao X, Weisleder N, Han X, Pan Z, Parness J, Brotto M, Ma J: Azumolene inhibits a component of store-operated calcium entry coupled to the skeletal muscle ryanodine receptor. J Biol Chem 2006, 281:33477-33486

32. Liantonio A, Giannuzzi V, Cippone V, Camerino GM, Pierno S, Conte Camerino D: Fluvastatin and atorvastatin affect calcium homeostasis of rat skeletal muscle fibers in vivo and in vitro by impairing the sarcoplasmic reticulum/mitochondria $\mathrm{Ca} 2+$-release system. J Pharmacol Exp Ther 2007, 321:626-634

33. Balnave $\mathrm{CD}$, Allen DG: Evidence for $\mathrm{Na}+/ \mathrm{Ca} 2+$ exchange in intact single skeletal muscle fibers from the mouse. Am J Physiol 1998, 274:C940-C946

34. Bastide B, Conti A, Sorrentino V, Mounier Y: Properties of ryanodine receptor in rat muscles submitted to unloaded conditions. Biochem Biophys Res Commun 2000, 270:442-447

35. Bustin SA, Benes V, Garson JA, Hellemans J, Huggett J, Kubista M, Mueller R, Nolan T, Pfaffl MW, Shipley GL, Vandesompele J, Wittwer CT: The MIQE guidelines: minimum information for publication of quantitative real-time PCR experiments. Clin Chem 2009, $55: 611-622$

36. Fraysse B, Desaphy JF, Rolland JF, Pierno S, Liantonio A, Giannuzzi V, Camerino C, Didonna MP, Cocchi D, De Luca A, Conte Camerino D: Fiber type-related changes in rat skeletal muscle calcium homeostasis during aging and restoration by growth hormone. Neurobiol Dis 2006, 21:372-380

37. Rios E, Pizarro G: Voltage sensor of excitation-contraction coupling in skeletal muscle. Physiol Rev 1991, 71:849-908

38. Delbono O, Meissner G: Sarcoplasmic reticulum Ca2+ release in rat slow- and fast-twitch muscles. J Membr Biol 1996, 151: $123-130$

39. Blaustein MP, Lederer WJ: Sodium/calcium exchange: its physiological implications. Physiol Rev 1999, 79:763-854

40. Sokolow S, Manto M, Gailly P, Molgó J, Vandebrouck C, Vanderwinden JM, Herchuelz A, Schurmans S: Impaired neuromuscular transmission and skeletal muscle fiber necrosis in mice lacking Na/Ca exchanger 3. J Clin Invest 2004, 113:265-273

41. Deval E, Levitsky DO, Marchand E, Cantereau A, Raymond G, Cognard $\mathrm{C}: \mathrm{Na}(+) / \mathrm{Ca}(2+)$ exchange in human myotubes: intracellular calcium rises in response to external sodium depletion are enhanced in DMD. Neuromuscul Disord 2002, 12:665-673

42. Pierno S, Desaphy JF, Liantonio A, De Bellis M, Bianco G, De Luca A, Frigeri A, Nicchia GP, Svelto M, Léoty C, George AL Jr, Camerino DC: Change of chloride ion channel conductance is an early event of slow-to-fast fibre type transition during unloadinginduced muscle disuse. Brain 2002, 125:1510-1521 
43. Lyfenko AD, Dirksen RT: Differential dependence of store-operated and excitation-coupled Ca2+ entry in skeletal muscle on STIM1 and Orai1. J Physiol 2008, 586:4815-4824

44. Cahalan MD: STIMulating store-operated $\mathrm{Ca}(2+)$ entry. Nat Cell Biol 2009, 11:669-677

45. Yuan JP, Zeng W, Huang GN, Worley PF, Muallem S: STIM1 heteromultimerizes TRPC channels to determine their function as storeoperated channels. Nat Cell Biol 2007, 9:636-645

46. Cheng KT, Ong HL, Liu X, Ambudkar IS: Contribution and regulation of TRPC channels in store-operated $\mathrm{Ca} 2+$ entry. Curr Top Membr 2013, 71:149-179

47. Lee KP, Choi S, Hong JH, Ahuja M, Graham S, Ma R, So I, Shin DM, Muallem S, Yuan J: Molecular determinants mediating gating of transient receptor potential canonical (TRPC) channels by stromal interaction molecule 1 (STIM1). J Biol Chem 2014, 289: 6372-6382

48. Kiviluoto S, Decuypere JP, De Smedt H, Missiaen L, Parys JB, Bultynck G: STIM1 as a key regulator for $\mathrm{Ca} 2+$ homeostasis in skeletal-muscle development and function. Skelet Muscle 2011, 1:16

49. Fraysse B, Rouaud T, Millour M, Fontaine-Pérus J, Gardahaut MF, Levitsky DO: Expression of the $\mathrm{Na}(+) / \mathrm{Ca}(2+)$ exchanger in skeletal muscle. Am J Physiol Cell Physiol 2001, 280:C146-C154

50. Quednau BD, Nicoll DA, Philipson KD: The sodium/calcium exchanger family-SLC8. Pflugers Arch 2004, 447:543-548

51. Lunde PK, Sjaastad I, Schiøtz Thorud HM, Sejersted OM: Skeletal muscle disorders in heart failure. Acta Physiol Scand 2001, 171:277-294

52. Aracena-Parks P, Goonasekera SA, Gilman CP, Dirksen RT, Hidalgo C, Hamilton SL: Identification of cysteines involved in Snitrosylation, S-glutathionylation, and oxidation to disulfides in ryanodine receptor type 1. J Biol Chem 2006, 281:40354-40368

53. Bellinger AM, Reiken S, Dura M, Murphy PW, Deng SX, Landry DW, Nieman D, Lehnart SE, Samaru M, LaCampagne A, Marks AR: Remodeling of ryanodine receptor complex causes "leaky" channels: a molecular mechanism for decreased exercise capacity. Proc Natl Acad Sci U S A 2008, 105:2198-2202

54. Vandebrouck C, Martin D, Colson-Van Schoor M, Debaix H, Gailly P: Involvement of TRPC in the abnormal calcium influx observed in dystrophic (mdx) mouse skeletal muscle fibers. J Cell Biol 2002, 158:1089-1096
55. Millay DP, Goonasekera SA, Sargent MA, Maillet M, Aronow BJ, Molkentin JD: Calcium influx is sufficient to induce muscular dystrophy through a TRPC-dependent mechanism. Proc Natl Acad Sci U S A 2009, 106:19023-19028

56. Carlsen RC, Gray SD: Decline of isometric force and fatigue resistance in skeletal muscles from spontaneously hypertensive rats. Exp Neurol 1987, 95:249-264

57. Carlsen RC, Gray SD, Pickar JG: Na+, K(+)-pump activity and skeletal muscle contractile deficits in the spontaneously hypertensive rat. Acta Physiol Scand 1996, 156:237-245

58. Gray SD, Carlsen RC, Deng J: Soleus muscle contractile properties in hypertensive rats. Am J Physiol 1994, 267:R735-R739

59. Gray SD, Carlsen RC, Atherley R: Effect of chronic blood pressure reduction on soleus muscle contractile properties in spontaneously hypertensive rats. Am J Physiol 1994, 267:R740-R746

60. Rosenbohm A, Rudel R, Fahlke C: Regulation of the human skeletal muscle chloride channel hClC-1 by protein kinase C. J Physiol 1999 514:677-685

61. Pierno S, Desaphy JF, Liantonio A, De Luca A, Zarrilli A, Mastrofrancesco L, Procino G, Valenti G, Conte Camerino D: Disuse of rat muscle in vivo reduces protein kinase $\mathrm{C}$ activity controlling the sarcolemma chloride conductance. J Physiol 2007, 584:983-995

62. Roudier E, Gineste C, Wazna A, Dehghan K, Desplanches D, Birot O: Angio-adaptation in unloaded skeletal muscle: new insights into an early and muscle type-specific dynamic process. J Physiol 2010, 588:4579-4591

63. Pravenec M, Křen V, Landa V, Mlejnek P, Musilová A, Šilhavý J, Šimáková M, Zídek V: Recent progress in the genetics of spontaneously hypertensive rats. Physiol Rev 2014, 63(Suppl 1):S1-S8

64. Pedersen BK, Febbraio MA: Muscles, exercise and obesity: skeletal muscle as a secretory organ. Nat Rev Endocrinol 2012, 8:457-465

65. Li YX, Cheng KC, Asakawa A, Kato I, Sato Y, Amitani H, Kawamura N, Cheng JT, Inui A: Role of musclin in the pathogenesis of hypertension in rat. PLoS One 2013, 8:e72004

66. Stiber J, Hawkins A, Zhang ZS, Wang S, Burch J, Graham V, Ward CC, Seth M, Finch E, Malouf N, Williams RS, Eu JP, Rosenberg P: STIM1 signalling controls store-operated calcium entry required for development and contractile function in skeletal muscle. Nat Cell Biol 2008, 10:688-697 